\title{
Process in Skill Acquisition: Motivation, Interruptions, Memory, Affective States, and Metacognition
}

\author{
JANICE LANGAN-FOX, KATHY ARMSTRONG, NIKOLA BALVIN, AND JEROMY ANGLIM \\ The University of Melbourne
}

$\mathrm{M}$ odels of skill acquisition, such as Ackerman's (1988) theory of skill acquisition, largely ignore the experiences and dynamic internal processes of a person while learning a skill (e.g., how they feel, what strategies they are using, the role of the external environment). Riding and Powell (1993) suggested that the information-processing model (a common conceptualisation of learning and thinking) is an inadequate model to explain the complexities of human brain functions. These models are largely holistic, and do not provide detail about the qualitative aspects of a person's learning experience. This paper attempts to highlight the importance of a dynamic description of skill acquisition and to "unpack" the skill acquisition stages, with a focus given to process rather than performance or outcome. Learning more about what is going on "inside people's heads" whilst learning a skill, and what feelings or affective states are present, can inform both skill acquisition theory and various practical issues, such as why some training programs fail and some succeed. The role of emotions, motivation, environment, and other factors; the concepts of skill and ability; and various theories of skill acquisition are discussed. This highlights missing elements in the typical cognitive experimental focus. The concept of process itself is explored, with a focus on learning in general. Process-oriented factors such as motivation, memory, interruptions, emotion, and metacognition are investigated in relation to skilled performance. Areas for future research and some practical implications for training are outlined.

Skilled performance is crucial for all human activities. Driving, playing a musical instrument, and typing all require coordinated processes of perception, cognition, and action (Proctor \& Dutta, 1995). In today's era of fast-paced technological change, the rapid acquisition of skills transferable to the workplace is becoming even more vital (Langan-Fox, 2001; Langan-Fax, Waycott, \& Galna, 1997). A broad aim of the current paper is to focus attention on the process of skill acquisition rather than on the outcome (i.e., skilled performance), and to use an understanding of internal processes to inform the design of training programs. The complexities involved in acquiring a skill encompass a literature extending back to the 19th century, with the work of Ebbinghaus (1885/1913) on learning and memory, Bryan and Harter (1899) on the learning of telegraphic language, and Craik (1948) on human information processing.

Early studies with trainee morse telegraphists (Bryan \& Harter, 1899) showed that the number of signals correctly transcribed per minute rises steadily over the first 3 to 4 months of practice, remains roughly constant (at a plateau) for the next 2 months, and then begins to rise again. Since their work, it has often been proposed that skill acquisition proceeds through phases characterised by qualitative differences in performance. A major shift in skilled-performance research appears to have occurred around 1945. At the close of World War II, there existed a considerable number of experimental psychologists who had been exposed to problems in the human skill research into aircrew selection for the US Army Air Corps. Finally, the immediate postwar period saw the introduction of new statistical techniques for conducting analyses on human skill data. Thus, before 1925 , much of the research was exploratory in character, and following 1935, a stronger interest in theory was observed (Bilodeau, 1969).

Over the years, researchers working in the skills area have been remarkably homogenous in their theoretical viewpoints. Structuralism, Gestalt theory, and psychoanalytically oriented research have had little influence, and behaviourism has been a dominant theoretical viewpoint, hence the predominant focus on the cognitive rather than the emotional aspects of skill acquisition (Bilodeau, 1969). In summary, the initial systematic research on skill acquisition and skilled performance, which encompassed such topics as the description of learning curves, transfer of training, and motor performance, lasted approximately 30 years, with a revival of interest in skill occurring around 1945 . Since that time, there has been increasing emphasis on the mechanisms underlying skill and cognitive skill (Proctor \& Dutta, 1995). In more recent times, there has been increasing interest in the development of quantitative models to examine the mechanisms and knowledge structures underlying the acquisition of skill (R. Carlson \& Yaure, 1990; Proctor \& Dutta, 1995). For example, since the 1960 s there have been a number of attempts to develop theories that predict the relative importance of different abilities over the course of task practice (Fitts, 1964; Fleishman, 1972; Schneider \& Shiffrin, 1977). The identification of changes in the pattern of abilities contributing to performance at different stages of practice would suggest that training procedures could be structured to match the ability requirements at each stage (Fleishman \& Mumford, 1989). For instance, models of skill acquisition, such as Ackerman's (1988) theory of skill acquisition, describe the "stages" of skill acquisition by "blocking" three proposed stages that focus on the ability-performance relationship, but largely ignore the experiences and internal processes

Address for correspondence: Dr Janice Langan-Fox, Department of Psychology, University of Melbourne, Parkvilie VIC 3052 , Australia. Email: j.langan-fox@psych.unimetb.edu.au

JULY $2002 \Psi$ AUSTRALIAN PSYCHOLOGIST

VOLUME 37 NUMBER 2 pp. 104- 117

104 
of a person (e.g., how they feel, what strategies they are using. the role of the external environment). That is, they are largely holistic models, and do not provide detail about the qualitative aspects of a person's learning experience (see Waycott \& Langan-Fox, 1997).

The current paper attempts to highlight the importance of a dynamic description of skill acquisition and to "unpack" the skill acquisition stages, with a focus given to process rather than performance or outcome. Riding and Powell (1993) suggested that the information-processing model (a common conceptualisation of learning and thinking) is an inadequate model to explain the complexities in ways in which the human brain functions. We suggest that we need to find out what is going on "inside people's heads" whilst leaming a skill, and what feelings or affective states are present, thus helping to inform both skill-acquisition theory and various practical issues, such as why some training programs fail and some succeed. Firstly, the concepts of skill and ability are examined, and various theories of skill acquisition discussed, highlighting missing elements in the typical cognitive experimental focus. Then, the concept of process itself will be explored, with a focus on learning in general. Next, process-oriented factors such as motivation, interruptions, memory, emotion, and metacognition will be investigated in relation to skilled performance. Finally, areas for future research and some practical implications for training will be outlined.

\section{Theories of Skill Acquisition}

There appears to be a general consensus in the literature that the learning of a complex task proceeds in accordance with approximate segments of practice, and that there are three stages in this process. Most of the information-processing theories have approached skill acquisition as a process that begins with resource dependency and ends in skilled performance or automaticity. Although there is a degree of congruency about skill phases, there are other features of skill acquisition that do not share the same degree of consensus. Many theories are more descriptive than predictive in nature. Difficulties encountered in the effective use of models of skill acquisition concern the nature of abilities, the notion of the development of automaticity, and possible moderating variables. Despite attempting to provide a dynamic view of skill acquisition through imposing three stages of practice, these theories are relatively crude attempts to describe a constantly changing process and do not provide an adequate account of the experiences of individuals as they learn a skill.

Specific models of skill acquisition usually differ in terms of whether or not attention is required for processing, whether particular processes can be carried out concurrently or must be performed sequentially, and the extent to which one process affects the other. A consistent observation in the literature on skill acquisition is that skilled performance is often associated with the withdrawal of attention and appears to operate outside the bounds of conscious awareness (Masson, 1990). Such performance has been termed autonomous (Fitts \& Posner, 1967) or procedural (Anderson, 1982). It is characterised by consistent speed and accuracy and is not limited by the amount of attentional resources available (Ackerman, 1986). Therefore, skilled performance is generally not subject to interference from other activities and distractions (Fitts \& Posner, 1967). This is in contrast to performance during the initial stages of skill acquisition, which is slow, error-prone, and resource dependent, that is, influenced by the portion of attentional capacity or effort devoted to the task
(Ackerman, 1986). Information-processing theories have converged on a conception of skill acquisition as a threestage process during which the cognitive demands of task performance change, beginning with resource dependency and culminating in the automaticity that characterises skilled performance. Anderson (1982), Fitts and Posner (1967), and Schneider and Shiffrin (1977) have proposed qualitatively similar accounts of this process. These theories are summarised in Table 1. Although Ackerman (1988) was the first to make speed-of-processing explicit, this concept is embedded in many earlier theories of skill acquisition, as increasingly faster and more accurate performance as the task progresses is usually assumed, which implies that reduced resource dependence and increased automaticity would lead to increased speed of processing. However, the contribution of his work is that he provided an integrative information-processing theory that links general models of skill acquisition with ability determinants of individual differences in performance.

Edwin Fleishman has been another prominent figure in the last 50 years in the domain of motor skill acquisition and abilities (Proctor \& Dutta, 1995). He proposed that in perceptual-motor tasks, general abilities play a role early in learning but, as practice progresses, new task-specific abilities become important and these are different from both the cognitive and perceptual-motor abilities.

\section{The Contribution of Abilities to Performance During Skill Acquisition}

Fleishman's basic procedure has been to give extensive training on a factorially complex task, and to administer a battery of tests for reference. Measures taken at different levels of learning on the criterion task and scores from the battery of reference tests are then intercorrelated, and the resulting matrix is factor analysed. It is 'usually found that the number of factors with significant loadings decreases from early to late practice, and the nature of the factors also changes. In tasks with significant motor components, the shift seen with training is from early factor loadings on perceptual abilities to later loadings on motor abilities (Proctor \& Dutta, 1995).

\section{TABLE 1}

The Three Phases of Skill Acquisition, As Described by Fitts \& Posner (1967), Anderson (1982), and Schneider \& Shiffrin (1977)

Phase 1 The task is novel to the learner, and performance is cognitively demanding (Fitts \& Posner, 1967). Performance is governed by controlled processing (Schneider \& Shiffrin, 1977), or declarative knowledge (Anderson, 1982), represented in terms of a propositional network.

Phase 2 The learner is no longer so reliant on cognitive processes.

Performance is characterised by mixed controlled and automatic processing

(Schneider \& Shiffrin, 1977).

Practice involves the strengthening

of stimulus-response connections and task-specific productions which, when refined, allow for skilled performance (Anderson, 1982; Masson, 1990).

Phase 3 Performance no longer requires conscious control. Performance is said to be autonomous (Fitts \& Posner, 1967), procedural (Anderson, 1982), or governed by automatic processing (Schneider \& Shiffrin, 1977). 
However, Ackerman has commented on several flaws in Fleishman's methodology and research methods. Ackerman (1987) re-analysed some of Fleishman's data and found they didn't support Fleishman's hypothesis. that is, that at the final stage of practice, some new, task-specific ability develops. In other words, the best predictors of performance are intra-task measures that reflect these specific abilities. Ackerman (1988) argued against the notion of task-specific abilities in favour of three broad ability classes that contribute to performance at different stages of skill acquisition. He proposed that these three ability classes, general intelligence, perceptual speed, and psychomotor ability were linked to the three skill-acquisition phases. Ackerman's modified model of ability structure follows from the recent conceptualisation of human intelligence as being organised in a hierarchical fashion. In Ackerman's model, the dimension of speed accounted for a change in information processing during skill acquisition: general ability is associated with high complexity and low speed of processing, perceptual speed ability constitutes intermediate amounts of processing level and speed, and psychomotor ability is primarily associated with low complexity and high speed of processing. The theory describes the relation of ability classes to phases of skill acquisition and can be used to predict the association between individual differences in performance across levels of skill. In the initial declarative stage of skill acquisition (general ability), substantial demands are made on cognitive abilities such as memory, reasoning, and knowledge retrieval (Ackerman, 1988). This phase is associated with general abilities at the top of the cylinder. As practice progresses, measures of intellectual ability become less related to performance. The associative stage (perceptual speed) develops when learners adopt rules for performance, and performance is more reliant on perceptual speed ability than general abilities, with attentional load reduced (Ackerman, 1990). In the autonomous phase (psychomotor ability), the learner has essentially automatised the skill, and performance is fluent and relatively free of attentional demands (Ackerman, 1990). Psychomotor ability then becomes more important for performance.

\section{What is Missing from Traditional Theories of Skill Acquisition?}

Although the theories described above provide a way of integrating cognitive abilities and the acquisition of a skill, one cannot accurately predict where people are in the skill-acquisition process. For example, if Ackerman's (1988) model assumes increasing levels of automomaticity at different stages of practice, we need to know what type of factors will impede this progress, at what point in the skill-acquisition process, and what will inhibit or assist development of skilled performance. We need to know how much of an impact these factors may have and when the impact is most serious, that is, when a novice is at initial stages of learning a skill or later, or when the learner has become an "expert". For example, in the third phase of skill acquisition, according to Ackerman's (1988) model, an expert should be able to perform without great demand on attentional resources. Would an emotional upset or environmental interruption have the same impact on an expert as someone just beginning to leam a skill? Indeed, is it possible to control these processes, regulate emotions, teach metacognitive strategies, and reduce the impact of environmental disruptions? Or is this a "stochastic" issue, one that is so random, and involving such a high degree of chance, that an attempt at control is likely to be ineffectual?
The area of skill acquisition has been narrowly focused on asymptote performance or expert performance, rather than the range of variables influencing the stages of performance. The next section will consider some useful models of human performance, which generally approach performance from an information-processing perspective, and also whether these models adequately account for dynamic processes during skill acquisition.

\section{A Broader Conceptualisation of Skill Acquisition: Important Influences on Human Performance}

The information-processing approach describes the operator on the same terms as the machine, and provides a convenient framework for understanding and organising a wide range of human performance results. General models of information processing distinguish three stages intervening between the presentation of a stimulus and the execution of a subsequent response. Early processes associated with perception and stimulus identification can be classified as the perceptual stage. Following this, are intermediate processes involved with decision making and thought, classified as the cognitive stage. Information from this cognitive stage is used in the final action stage to select, prepare, and control the movements necessary to effect a response. However, it is not always clear whether a change in performance should be attributed to the perceptual, cognitive, or action stage (Proctor \& Van Zandt, 1994). Attention also impacts on performance, and models of attention abound, such as bottleneck and resource models. Bottleneck models specify a particular stage in the information-processing sequence at which the amount of information we can attend to is limited. Resource models view attention as a limited-capacity resource that can be allocated to one or more tasks, rather than as a fixed bottleneck.

Broadbent (1958) introduced the filter theory, a model in which stimuli enter a central processing channel one at a time to be identified. Thus, filtering of extraneous or unwanted messages must occur early, prior to this identification stage. An alternative view that has been prominent is multiple-resource theory. Multiple resource models propose that there is no single attentional resource; rather, several distinct subsystems each have their own limited pool of resources. Wickens $(1980,1984)$ proposed a threedimensional system of resources consisting of distinct stages of processing (encoding, central processing, and responding), codes (verbal and spatial), and input (visual and auditory), plus output (manual and vocal modalities). The model assumes that two tasks can be performed together more efficiently to the extent that they require separate pools of resources.

Although the models discussed above consider the role of perception and cognition in allocating attentional resources towards skilled performance, they do not adequately examine the intemal processes and characteristics of trainees, and the role of the external environment. By treating the trainee as a machine, these models do not account for human responses to the task, such as frustration or boredom, or the effect of interruptions. Although these models appear to be dynamic, they are overly simplistic and do not account for the process of skill acquisition from a human perspective. But what does process mean?

\section{The Notion of Process}

Process could be defined as a series of actions, changes or functions bringing about a result, or as the act of proceeding; 
continued forward movement: procedure; progress; advance, or a particular course of action intended to achieve a result. It is a dynamic concept, focused on the end result. Apparently, a process is thought to be always paired with an outcome or result. The first definition is most aligned with our current position, with the idea of a "series of actions, changes or functions". The nature of these actions, changes of functions is the focus here, rather than the result.

We are suggesting that it is important to know about the series of changes, actions, and functions that occur during learning (see e.g., Langan-Fox in press). How do a person's emotions, metacognitions, levels of conciousness, and so on vary over the course of practice? Rather than examining the relationship between static measures of cognitive ability and performance at different stages of practice, it would be far more interesting to tap into changing relationships between emotions or metacognitions and performance; for example, what different patterns emerge, and how can this be generalised to other tasks or situations?

It would seem useful at this point to provide a framework for conceptualising the role of process during skill acquisition, which can tie together the factors that are described later on. Figure 1 shows how internal and external influence can impact skilled performance, and is a useful way to organise the variables (levels of consciousness, cognitive abilities, emotion, metacognition, motivation, memory, interruptions, goals, practice format, task characteristics), and how they relate to each other and impact on performance, which expands on the traditional information-processing approach common to many models of skill acquisition. The figure is meant to be a guide only, for stimulating ideas about possible variables to be included in research, in some broad way. A more descriptive model providing some determinants of performance is provided in Figure 2.

\section{Process during Learning in General and During Skill Acquisition}

It is pertinent at this juncture to discuss recent research examining the role of process during learning. Rosetta (2000) investigated the importance of metacognitive and affective training on mathematics performance amongst a group of university students. Training focused on knowl-

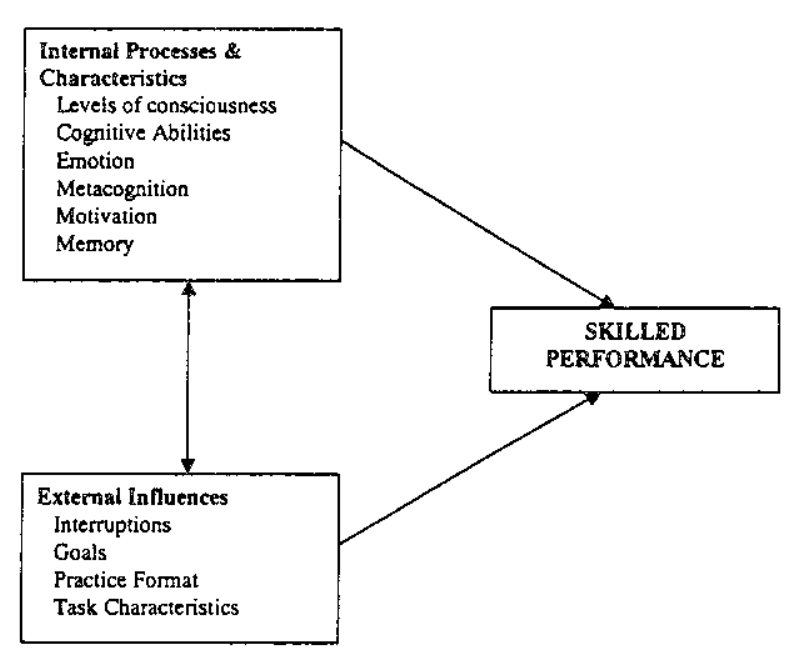

\section{IGURE 1}

In integrated process framework for skill acquisition and erformance. edge about cognition, monitoring, beliefs, emotions, and attitudes, and appeared to assist students to pass the course Ingleton (1995) found that emotionally laden beliefs profoundly influenced learning in higher education. Sylwester (1994) suggested that our emotional system is a complex, widely distributed, and error-prone system that defines our basic personality early in life and is quite resistant to change, and proposed that emotion research should be applied in classroom situations to improve learning. Schumann (1994) suggested that cognitive processes are neutral, while the affective filter of the brain's stimulus appraisal system interacts with cognition to promote or inhibit learning. Ferro (1993) echoed this view, by describing the human brain as triune, controlling physical activity, emotion, and cognition. Strategies for dealing with the affective element, such as creating self-awareness, positive self-concept, trust, and acceptance, are suggested as important influences on learning. Dimensions of interest and boredom in instructional situations were identified by Small (1996), who found that feelings of pleasure and arousal were linked to generating and sustaining current learning interest. Competence and self-determination were found to be more closely related to fostering a continuing motivation to learn.

According to Beebe and Ivy (1994), student emotional responses to teacher classroom behaviours may offer a theoretical framework for explaining student learning. Such a framework may encompass other models, such as arousal/motivation or identification, in offering an explanation of why students learn when teachers exhibit certain behaviours. Hogan and Kwiatkowski (1998) suggested that emotional aspects of teaching large groups, in particular, have been largely neglected and ignored. The authors argue that it is legitimate to consider the role of emotion in higher education and its particular effects in large teaching groups. While it is perhaps easier and safer to pretend that all is well, there are clear emotional consequences to working in these large groups, for both students and lecturers. For instance, students may experience powerful feelings of alienation, anger, and envy in large groups and compensate in various ways, some of which will be antithetical to achieving effective learning and a stimulating educational experience. Similarly, lecturers can also seek to cope with their own feelings of fear and uncertainty by behaving equally maladaptively.

Greene, Rucker, Zauss, and Harris (1998) found that communication anxiety affected individuals' progress through skill-acquisition stages. Russell (1995) found that understanding the stages of learning to use technology (by identifying six stages adult learners pass through as they become confident using electronic mail) empowers the leamer through the knowledge that feelings of tension and frustration will be overcome.

The next section considers several issues that need to be considered to obtain a comprehensive account of qualitative and experiential aspects of the skill-acquisition process, for example, the role of changing levels of conciousness, motivation, emotion, metacognition, memory, and external influences (e.g., massed vs. distributed practice and intemuptions).

\section{Internal Influences on the Acquisition of a Skill: Changing Levels of Consciousness and Automaticity, Motivation, Emotion, Metacognition, and Memory}

\section{Changing Levels of Consciousness}

Changing levels of consciousness across task practice need to be examined, insofar as determining exactly when people 
make the transition from one to another stage (e.g., from general ability to perceptual speed). As Rasmussen (1983) suggested, on many occasions, decisions need to be made consciously, especially if the task is highly complex and evaluative. Rasmussen's work on cognitive task analysis proposed a trichotomy among skill-based, rule-based, and knowledge-based behaviour. These types of selection of action represent points on a continuum related to the degree of automaticity of various actions. Operators must be sensitive to when skill- and rule-based behaviour is no longer appropriate, and they must therefore move into a knowledge-based problem-solving domain (Rasmussen, 1983). Rasmussen also focussed attention on the need to problemsolve flexibly by moving up and down to different levels of abstraction. The dynamic nature of work and other task environments guarantees not many skills will be completely automatised. New skills must be acquired, and often must be integrated with existing skills. Also, novel situations may be encountered to which performance must be adapted, so that automated responses are no longer appropriate. Consequently, as stressed by Rasmussen (1983), task performance will involve combinations of the different modes of behaviour, depending on situational factors. The major difference between Rasmussen's formulation and those of Fitts and Posner (1967) and Anderson (1982) is that Rasmussen emphasises that the performer can switch between modes of behaviour as dictated by task demands, whereas these other authors both emphasise skill acquisition as a clear progression through stages, with little flexibility to move backwards or forwards through the various stages. However, in relation to other models, the question that needs to be asked is how cognitive and evaluative (i.e., complex) a task can be, and still fall within the realms of theory, as this is important in terms of the generalisability to a wide variety of tasks. If a theory can only be applied to relatively simple tasks with consistent mapping of stimuli to responses, then perhaps the parameters or limitations need to be more clearly defined so that it can be used for more practical purposes such as the design of training programs.

Is automaticity necessary for skilled performance, and how long this does take to develop? The more a process has been practiced, the less attention it requires, and there is speculation that highly practiced processes require no attention at all. It has been shown that performance of a cognitive skill improves as a power function of practice and only shows modest declines over long retention intervals. The so-called power law of learning illustrates that the benefit of further practice rapidly diminishes, and that, no matter how much practice we have had, further practice will not help (Anderson, 1995).

Healy and Boume (1995) suggested that automaticity can develop in as few as 200 trials if appropriate training procedures are employed. However, for automatic processing to develop, mapping of target stimuli to responses must be consistent. Two contrasting views of the nature of automaticity have been proposed. First, the most common are theories that propose that automaticity reflects a greater efficiency in processing and reduced demands on attention (Schneider, 1985; Shiffrin \& Schneider, 1977). An alternative approach is Logan's (1988) instance theory of automaticity. It suggests that practice increases the number of memory traces for each stimulus, increasing the probability that the stimulus-response relationship can be directly retrieved from memory.

According to Schneider and Shiffrin's (1977) model of controlled and automatic processing, the staged development of skilled automatic performance can be interpreted as a sequence of transitions from controlled to automatic processing. Automatic processing is proposed to require considerable training to develop and, once learned, is greatly resistant to change (see also Anderson's 1982 model of the acquisition of cognitive skill). Sometimes up to 25 hours is required for automaticity to develop. However, this is not a unanimous viewpoint; in fact, Ackerman (1988) proposed that long periods of practice may not always aid the development of automaticity, especially if the task is complex. It is interesting to note that Ackerman (1988) stated that instead of being beneficial in terms of allowing automaticity to develop, sometimes in the case of highly complex tasks that require 20 hours or more for a transition through the stages to occur, other variables such as motivation may have an obscuring effect, perhaps because of reduced task consistency. Task inconsistency leads to increased controlled processing demands, delaying the development of automaticity. Ackerman (1988), in his fourth experiment, measured the consistency of a task through a reduction in variability in subjects' performance.

However, other individual difference variables, whilst not detailed or tested within the framework of Ackerman's (1988) theory, could be theorised to influence skilled performance. These include (a) motivation, (b) efficacy of initial productions formulated in Phase 1 of the skill-acquisition process, and (c) the learner's ability to develop efficient and accurate compilation and tuning of the productions.

\section{Motivation: Goals and incentives}

Early research into motivation focused on drive changes on performance and included the work of Hull, Perin, and Webb, who used rats as subjects (McGeoch, 1952). In regard to motivation, Kanfer and Ackerman (1989) have proposed a model of ability-motivation interactions for attentional effort, which assumes that changes in the amount of capacity used, and policies for allocation of attention, are accomplished through motivational processes. Kanfer and Ackerman (1989) reported that the setting of specific and difficult goals in later phases of skill acquisition may facilitate complex task performance, and revealed that the beneficial effects of goal setting during the later phase are most likely to accrue to low-ability rather than high-ability persons. Their studies suggested that goal setting affects ability-performance relations during practice by influencing attentional resource allocation, that "early goal" participants had lower general ability-performance correlations than control subjects, and that the perceptual speed ability-performance correlations for both early and late goal conditions showed an attenuation in the level of increase, compared to correlations of the no-goal condition. These findings suggest that goal setting may have a role as a moderating variable in ability-performance relations.

Twenty years of empirical research has established that specific, challenging goals lead to higher levels of task performance than no goals, vague goals, or easy goals (R. Wood, Mento, \& Locke, 1982). Given adequate ability and commitment to the goal, the harder the goal, the higher the performance. For example, in 99 out of 110 studies, specific, hard goals produced better performance than medium, easy, "do your best" or no goals (Locke \& Latham, 1991). Kernan and Lord (1989) found that individuals with no specific goals generally evaluated their performance more positively than those with specific, hard goals in response to varying degrees of negative feedback. Schmidt, Kleinbeck, and Brockman (1984) showed that goal specificity and difficulty had a significant effect on the allocation of cognitive resources. When two tasks were performed simultaneously, more resources were allocated to the task 
with a specific and difficult goal than to the one with no specific goal.

Self-regulatory processes are critical determinants of performance and of the development of competencies. Self-regulation is an important mechanism for initiating changes in resource allocation policy toward a task and occurs when people adopt difficult goals and perceive themselves to have adequate skills to complete the task. Components of self-regulation include self-monitoring and self-evaluation (Kanfer \& Ackerman, 1989). Informationprocessing demands of the task, individual differences in cognitive abilities, and self-regulation processes together determine the distribution of attentional effort across on-task and off-task activities during task engagement (Kanfer, 1990).

\section{Motivation and Dispositional Tendencies}

Individual differences in cognitive abilities, dispositional tendencies, and task attentional demands may affect learning and performance through their influence on the character and quality of self-regulation during skill acquisition. The Kanfer and Ackerman framework is consistent with the theoretical foundation for action orientation and suggests that individual differences in action orientation affect complex skill acquisition through self-regulatory mechanisms (Kuhl, 1994a). Action control theory suggests that the distinction between "action" and "state" orientation may further explain the relationship between goals and behaviour beyond that possible by goal setting (Farr, Hofmann, \& Ringenbach, 1993). The construct of "action versus state orientation" affects self-regulatory abilities by mediating the initiation of a preferred activity and its maintenance, despite the presence of tempting distracters in the environment, and allows disengagement from it when the intended goal can't be attained (Kuhl, 1992).

Kuhl's (1985) model of action control describes strategies, goal-directed intentions, and voluntary action. Research has demonstrated that individuals may be oriented toward the environment (action, behaviour) or toward internal states (e.g., rumination, introspection) (Kuhl, 1994b). Internal or state orientation often has a task-irrelevant focus that detracts from plan execution and increases the likelihood of helplessness effects (Austin \& Vancouver, 1996), while action-oriented individuals focus their attention on activities related to the immediate task, and experience emotional and affective states that support goal-directed action (Geen, 1995). There has also been the suggestion by Antoni and Beckman (1990) that action-control processes (a self-regulatory construct) moderate the effects of goal setting, and that hard, specific goals will increase action orientation. The moderating variables mentioned above have not yet been fully tested, but nevertheless will be important in future research into skill acquisition. Another important variable is emotional responses to skill acquisition, which will be discussed below.

\section{Emotion and Skilled Performance}

Emotion is one of the most central and pervasive aspects of human experience. While emotions colour, deepen, and enrich human experience, they can also cause dramatic disruptions in judgement and performance. In large part, research on individual differences in skill acquisition has progressed with little attention given to emotion, despite the obvious link between emotion and cognition, and its relation to sustained performance during skill development (Oatley, 1987; Humphreys \& Revelle, 1984). Early work on emotion and individual differences in performance focused on general subjective states and vigilance performance, for instance, boredom. Other work has concentrated on the effects of stress on skilled performance through the impact of noise, loss of sleep, heat, anxiety, arousal, and so on (e.g., Humphreys \& Revelle, 1984). Since the early 1980s, a great deal of research has been devoted to understanding the cognitive appraisal of events that elicit emotions (Ortony, Clore, \& Collins, 1988). Emotions (positive or negative affective reactions) that a person can experience depend on the aspect of a situation (events, actions, or objects) to which one attends. including the outcomes of events, the agency of actions, the attributes of objects, and various combinations.

Emotions may be influenced by what one wants, as well as by what one thinks. Smith and Ellsworth (1985) constructed dimensions of cognitive appraisal (e.g., attentional activity, pleasantness, anticipated effort, responsibility, control) that were useful in distinguishing subjects' emotions. Later research confirmed these dimensions (Smith \& Ellsworth, 1987).

Modern theories, however, have little to say in the way of specific proposals about cognition and emotion. It is quite possible that the root cause of the dissociation between cognitive and emotion theories lies in the emphasis that has been placed in recent years on the computer metaphor of "human information processing". This approach to cognition has been noticeable in its failure to make progress on problems of emotion. Oatley (1987) proposed that the study of emotions is not just an "extra" in psychology and cognitive science. In human mental life, the more traditional cognitive activities, such as thinking, are often, or perhaps almost always, affected by emotions, and they occur in the context of several simultaneous goals (Oatley, 1987). Cognitive approaches to emotion are mainly concerned with the identification of variables that influence evaluation processes in humans, but it should be emphasised that an evaluation is not an emotion. Evaluations are a part of the total process that involves an organism interacting with its environment in biologically adaptive ways. Cognition is considered as more or less synonymous with thinking, and includes such functions as perceiving, conceptualising, and remembering (Plutchik \& Kelleman, 1980).

The importance of human consciousness to the study of emotions is that many of their important determining functions may take place only in consciousness, Mandler (1975) saw emotional consciousness as developing out of more basic and more general processes involving arousal and cognitive structures. The experience of emotion and the conditions for many emotional behaviours are the interactional result of autonomic arousal and cognitive interpretations (Mandler, 1975).

It would seem important to the study of skill acquisition to investigate the experience of emotions and the cognitive appraisal of such emotions whilst acquiring a skill. This work would reveal a link between emotion and performance, and may provide an account of an individual's experience as he or she proceeds through the three phases, and of how the particular skill actually being acquired effects this experience.

It has been suggested that emotions may sometimes be disruptive to performance, through emotions such as frustration and anxiety (Ellis \& Ashbrook, 1988). In general, the amount of attentional resources people can invest in an activity is assumed to be limited and variable, being influenced by factors such as arousal and emotional states. Researchers have focused on the impact of negative affect on attentional resources (Ellis \& Ashbrook, 1988). Ellis and Ashbrook's resource-allocation model proposes that negative affective states are likely 
to reduce the resources that can be allocated to a given task. This is because mood-congruent thoughts, possibly induced by the task itself, intrude into consciousness and may induce reflection about one's current mood state, bodily sensations, and sources of one's mood. Chronic negative affect can be associated with greater self-focused attention and selfmonitoring (J. Wood, Saltzberg, \& Goldsamt, 1990), which may involve attempts at self-understanding that require the investment of attentional resources.

Together, intruding thoughts caused by negative affective states that were a consequence of negative cognitive appraisal of an event may interfere with information processing and result in demand for more than minimal amounts of attentional resources, thus inhibiting performance and automaticity. These processes may be evident in subjects' reports of emotional experiences, metacognitive processes, and causal attributions. On average, negative emotions can therefore be assumed to lead to a much more elaborate processing of situational and self-related information than positive emotions do, although positive emotions might also induce much task-irrelevant thinking if they are sufficiently intense (Ellis \& Ashbrook, 1988).

A number of theorists, noting the role of discrepancy or disruption in generating the arousal associated with emotion, have suggested that the function of emotion is to trigger or modulate self-awareness or control functions. For example, Mandler (1975) described autonomic arousal as "a signal to the mental organisation for attention, alertness, and scanning of the environment" (p. 118). Thus, the effect of negative affect during processes of skill acquisition would be to increase self-monitoring and evaluation and thus greater attentional resource allocation. Intrinsic motivation, motivation directed at performing an action for its own sake, is intimately linked to the experienced cognitive and emotional properties of tasks. It follows that emotions connected to task contents can trigger and sustain intrinsic motivation. Extrinsic motivation may be defined as motivation that aims at performing an action because of its outcomes, or aiming beyond the current task to tackling the next one (Pekrun, 1992). Pekrun (1992) suggested that the effects of positive emotions may be beneficial in most cases and that the impact of negative emotions such as anxiety or dissatisfaction may well be ambivalent.

\section{Metacognitive Awareness of Acquired Skills}

Another sense of consciousness in cognitive skill involves an individuals' metacognitive awareness of acquired skills. The term metacognition has increasingly been employed to refer to a person's "cognition about cognition", that is, the person's knowledge of cognitive processes and states such as memory, attention, knowledge, conjecture, and illusion (Wellman, 1985). Such awareness is often possible and presumably necessary for strategic restructuring of cognitive routines (D. Carlson, 1997). Five different overlapping sets of knowledge are thought to form a person's metacognition (Wellman, 1985), including cognitive monitoring abilities to accurately assess the state of information within one's own cognitive system, and knowledge of one's moment-bymoment understanding of cognition.

With increasing skill, it appears that conscious control is streamlined as performance depends on different or larger units of information. As the units of knowledge and performance change with practice, the experience of skilled performance also changes. Researchers are beginning to realise that even so-called automatic processes are in fact under control in some sense (D. Carlson, 1997). Humans are often able to "read" their own mental states, or monitor their ongoing cognitive processes. Cognitive monitoring refers to abilities to accurately assess the state of information within one's own cognitive system. This knowledge of the contents of one's mind is part of the person's moment-bymoment understanding of his or her cognition, and thus part of his or her conception of cognition itself (Forrest-Pressley, MacKinnon, \& Waller, 1985). Less able leamers and those who show poor generalisation and transfer typically have underdeveloped metacognitive skills (D. Carlson, 1997). The role that metacognition might play in the acquisition and transfer of perceptual-motor skills is, however, relatively unexplored territory.

Devolder and Pressley (1992) explored the role of causal attributions and strategy use in relation to memory performance. They found that attributions to controllable factors (i.e., strategy use) were associated with increased memory performance compared to when memory was attributed to uncontrollable factors (i.e., ability). They suggested that believing that performance is controllable may undermine the efficient use of effort in cognition, consistent with current metacognitive theory.

Although the role of metacognition has been investigated with memory tasks, little research has been conducted with more real-world tasks (e.g., text editing), nor has work been done investigating causal attributions and strategy use during the process of acquiring a skill.

\section{Memory}

Memory is an essential part of the information-processing system that governs learning and is of utmost importance for the maintenance of learning over time. In order to store, retain, recall, and relearn information, many unconscious and conscious processes need to be undertaken. The ability of people to apply their memory to skills, either as an inherent capacity or conscious strategies such as mnemonics, affects an individual's capacity to remain skilled in a task over time. As such, assessing these individual differences may shed insight on how retention of skills may be improved. Retention and transfer of skills acquired from training is of crucial importance if training programs and instruction are going to lead to boosts in organisational productivity and individual benefit. As part of the information-processing system, memory plays a crucial role in these processes. While memory plays a part in all leaming and retention, different components of memory may be more important at different times. As Woltz (1988) has suggested, individual differences in component memory abilities may relate to task performance in dynamic ways. In a study by Rogers, Hertzog, and Fisk (2000), young and older adults showed a high correlation for general ability, with working memory correlated at .79 and associative memory at .69 . However, other studies utilising different component measures suggest correlations substantially lower, such as .09 for memory span for letters and .24 for memory span for words (Palmer, MacLeod, Hunt, \& Davidson, 1985). Thus, it might be inferred that memory ability, although related to general cognitive capacity, will affect task performance in ways not captured simply by measures of intelligence.

Throughout the psychological literature, there have been several utilisations of the concept of memory for the purpose of explaining individual differences in skill acquisition. Tests of memory ability are often used in neuropsychology to assess brain damage, assess specific cognitive disabilities, and evaluate general cognitive functioning (Hilsabeck, Schrager, \& Gouvier, 1999). By exploring individuals with exceptional memory skills, expertise research (Ericsson, 1985; Ericsson \& Chase, 1982; Ericsson, Krampe, \& Tesch-Romer, 1993) has shown the 
way memory competence may be a learned and practiced skill that is often limited to a specific task or domain. Also, some researchers in cognitive psychology (eg., Carroll, 1993; Kyllonen, 1996) have incorporated individual differences in working memory, exploring its role in setting limitations and potentials of information-processing capacities. Finally, measures of component memory ability have been used in skill-acquisition research, often using the ability-performance correlation paradigm (e.g., Echt, Morrell, \& Park, 1998; Woltz, 1988). From these diverse theoretical orientations, it is possible to see the various ways that the fundamental information-processing system of memory may relate to individual differences in cognitive skills.

Anderson's ACT (1982) theory of skill acquisition is useful in understanding the role of component memory abilities in skill-acquisition processes, and it was successfully applied in Woltz's (1988) study exploring the relationships between task performance and different types of working memory. Anderson's theory suggests that skills are composed of two types of knowledge, namely, procedural knowledge, represented by condition-action associations, and cognitive factual units called chunks. As skill acquisition progresses, a process of composition occurs, whereby effective condition-action associations are reinforced and aggregated into larger cognitive chunks (Lewis, 1978; Neves \& Anderson, 1981). This process of proceduralisation results in a reduction in cognitive resources being placed on short-term memory and allows more advanced strategic and executive performance to occur. Anderson and Pirolli (1984) suggested that a process of spreading activation occurs during learning, whereby task-associated information chunks of the individual's semantic network are activated. The speed at which conditions lead to their associated action (production rule) is suggested to be predicted by the efficiency of this spreading activation process. This theory has successfully been utilised in studies of serial memory tasks (Anderson \& Matessa, 1997) and human-computer interactions (Anderson, Matessa, \& Legiere, 1997).

Using ACT theory as a foundation for the purpose of guiding future research, several different hypotheses may be suggested relating individual differences in component memory abilities with task performance. The present review predicts that, during Phase 1 of skill acquisition, when high demands are placed on attentional resources and remembering declarative rules, working memory will be most predictive of task performance. Woltz (1988) supported this prediction, finding that controlled attention in working memory predicted initial factual rule learning. In Phase 2 , when there is a need to chunk and aggregate production rules, associative memory is likely to be more predictive. As they predicted, Rogers et al. (2000) found that associative memory ability was predictive of skill acquisition on an associative learning task. Finally, procedural memory could be predicted to show progressively higher correlations as performance enters Phase 3 and approaches asymptote performance due to the need for faultless execution of complex skill chunks. A study by Hertzog, Cooper, and Fisk (1996) may be interpreted as supporting this, when they found that semantic memory access remained a strong predictor of performance on a memory search task. Instead of procedural semantic memory representing intelligence, as they suggested, it could be understood as a component of procedural memory required for faultless execution of the performance task.

\section{Retention}

Because skill acquisition in a real-world context occurs over time and involves extended periods of non-practice, the maintenance and retention of performance at a competent level is highly important. Although in a review it was shown that superior retention is achieved through better initial leaming (Healy \& Sinclair, 1996), research into individual cognitive differences and encoding strategies supports the idea that there is significant variation in the capacity of individuals to transfer and retain acquired skills (Bors \& MacLeod, 1996). To account for these differences, the concept of general memory ability may be useful or, as found by Kyllonen, Tirre, and Christal (1991), such differences may be specifically related to some measure of long-term memory retrieval and encoding ability. However, it has proved challenging to attain valid, reliable, and useful measures of either of these memory abilities. For example, it was found that two tests of general memory ability, the WMS-R and the MAS, were not highly related (Golden, White, Combs, Morgan, \& McLane, 1999). Researchers in the expertise literature who emphasise the learned nature of memory skill have shown how scores on memory tests can be dramatically enhanced with practice (Ericsson \& Charness, 1994). This was further supported in a study by Willoughby, Waller, E. Wood, and MacKinnon (1993), who found that familiarity with the content of memory tests can affect recall, presumably because, with practice, information becomes more meaningful and easier to encode.

In a literature review, Bors and MacLeod (1996) proposed that the amount of knowledge attained by an individual influences the effectiveness of long-term memory. In line with this notion, it was found that the amount of factual knowledge already attained predicted final retention in paired associate learning tasks (Kyllonen et al., 1991; Kyllonen \& Tirre, 1988). This finding was interpreted by Kyllonen et al. (1991) as resulting from improved capacity to draw associations between new and established information. It was also found that speed of search through long-term memory improved task performance (Kyllonen et al., 1991). While the extent to which these findings apply to procedural skills is unresolved, it could be deduced that greater general motor skills would allow for more rapid skill acquisition and greater retention of motor skills. However, it may not only be internal influence such as memory that can affect skill-acquisition performance; the external environment needs to be considered also. The next section will discuss the role of practice distribution and external interruptions in a training environment.

\section{External Influences on the Acquisition of a Skill: Distribution of Practice and Interruptions \\ Distribution of Practice}

In determining the optimum length of a training session, it should be asked whether it is easier to learn a new task by practising it continuously until mastered, or whether it is better to divide the time into short periods interspersed with rest or other activity. The superiority of continuous or spaced practice clearly depends on a balance amongst several factors. The distribution of practice has a long history of research in the study of motor learning (Adams, 1987). The relative efficacy of distributed over massed practice was first demonstrated by Ebbinghaus in 1885 (McGeoch, 1952). Many studies show that massed practice results in considerably poorer performance during acquisi- 
tion. Lee and Genovese (1989) conducted a meta-analysis of the literature to determine whether distributed practice produces better learning than massed practice. Their metaanalysis showed that massed practice does result in poorer learning than distributed practice, although the effect is smaller on retention tests than during acquisition. Two main reasons have been advanced to account for the cases in which spaced practice is superior. First, if material is indeed held in some kind of dynamic short-term store while more permanent traces are being established, "consolidation" of the trace will outlast the actual presentation of the material to the subject and will continue during part of the gap between one practice session and the next. The second type of advantage suggested for spaced practice is that the pauses allow certain after-effects of previous training trials to die away and thus reduce any adverse influences they might have on subsequent trials (Welford, 1968). Is there an optimum length of training sessions? Henshaw and Holman (1933) found that 80 minutes training per day at a chain-assembly task yielded a net improvement of 160 minutes.

Research examining how the distribution of practice may affect ability-performance relations in this area is sparse. From their research, Fleishman and Ellison (1960) concluded that the same abilities contributed to performance during massed practice as contributed to performance during distributed practice trials. However, ability-performance relations during the trial following the break after the massed practice trial were markedly affected, with predictions for all ability variables dropping significantly compared to the other trials of practice. Fleishman and Ellison (1960) suggested that individual differences in recovery from "fatigue" or inhibition-like states seemed to depend on abilities different from those that predict learning. In contrast, a more recent study suggested that the abilities that contribute to performance during massed practice are different from those that contribute during distributed practice trials (Mumford, Constanza, Baughman, Threlfall, \& Fleishman, 1994). This is in contrast to Ackerman's (1988) findings that, after each break in practice (distributing practice), perceptual speed was more related to performance than it was prior to the break. However, Mumford et al. (1994) also suggested that the benefits of distributed practice are not as evident for less complex tasks, where learning can proceed through the acquisition of stimulus-response linkages and associational mechanisms, and that this may explain this difference.

As skill acquisition proceeds, the knowledge required to perform the skill is transferred to long-term memory where it can remain for a much longer period of time. Baddeley (1990) suggested it is possible that subjects boost their learning and thus their performance on tasks with information temporarily located in working memory, even when mainly using information held in long-term memory store. Baddeley also argued that interfering material will impair retention of material by causing information in longterm memory to be forgotten. Underwood and Schulz $(1959,1961)$ provided empirical support for the suggestion that measurable forgetting can occur over the intervals used to define distributed practice. Their results indicated that forgetting of responses occurred over rest intervals and that the longer the interval, the greater the amount of forgetting that occurred. Others have suggested that distributed practice can lead to forgetting if the inter-trial intervals become "long enough" Mazur and Hastie (1978), while reviewing the literature on distributed practice, suggested that subjects' projected asymptote for performance on a simple perceptual task with a trial length of 60 seconds increased with longer rest periods up to 60 seconds, and then decreased, was evidence of forgetting over the longer rest intervals. Research by Ackerman (1988) suggested that learning a task could largely proceed through the development of stimulus-response linkages and that relatively large breaks in practice weakened these associations as subjects forgot some of what was learned. After the breaks, perceptual speed became more influential as the stimulus-response connections were strengthened. Ackerman's (1988) findings, therefore, can be used as partial support for the suggestion that forgetting may occur if practice is distributed. Breaks may be seen as similar to "inconsistent" task components in that they decrease the strength of learned associations.

\section{The influence of Interruptions}

Landscape offices are characterised by external interruptions such as phone calls, email messages, fax deliveries, and colleague enquiries (Gregory, 1998; Kaye, 1999), so it is highly likely that interruptions in the work environment will occur while workers are learning new skills. An interruption is described as "an externally generated, randomly occurring, discrete event that breaks continuity of cognitive focus on a primary task" and demands immediate allocation of attentional resources (Corragio, 1990, cited in Speier, Valacich, \& Vessey, 1999, p. 339). These demands placed by interruptions on attentional resources often result in information overload. Kahneman (1973) identified two types of attention models accounting for the phenomenon of information overload: capacity and structural. The capacity theory of attention assumes a general limit on the amount of mental work the human brain can process at a time, where processing of concurrent activities may result in interference as the demands on attentional resources exceed the available capacity. The structural theory of attention assumes that human attention resource is structured like a "bottleneck", allowing only a limited amount of information through for cognitive assessment (Kahneman, 1973). Interference occurs when the same physiological mechanism is required to process two incompatible operations at the same time. Both theories predict that concurrent demands on attentional resources, such as those caused by interruptions, interfere with performance on a complex task, which requires large attentional availability and focus. Research (e.g., Speier et al., 1999) recognises two categories of interruptions: (a) those that effect cognitive processing (e.g., Kahneman, 1973); and (b) those that present as social characteristics, influencing the manner of decision makers' response (e.g., Kirmeyer, 1988).

Interruptions have been investigated in association with diverse psychological phenomena, such as information overload (Speier et al., 1999), speed (Zijlstra, Roe, Leonara, \& Krediet, 1999), and accuracy (Cellier \& Eyrolle, 1992) of performance; work stress (Kirmeyer, 1988); emotional states (Seibert \& Ellis, 1991); age (Czaja \& Sharit, 1998); gender (Joesch, 1997); and boredom (Fisher, 1998). No studies have directly examined the effect and demands of interruptions on attentional resources during the process of skill-acquisition performance.

Three types of theories are commonly employed to explain the effect of interruptions on performance: (a) arousal theory (Cohen, 1978), (b) distraction/conflict theory (Baron, 1986), and (c) attentional overload theory (Cohen, 1978). Arousal models predict that external stressors (e.g., interruptions) change phasic arousal levels, raising or lowering activity levels, which influences performance (Cohen, Evans, Stokols, \& Krantz, 1986). During the optimal level of arousal, it could be predicted that performance is most likely to be adversely effected during Phases 1 and 2 of skill 
acquisition, namely, prior to asymptote performance. The distraction/conflict theory was developed to explain the effect of distracters such as heat and noise on performance. It states that the occurrence of a distracter elevates stress levels and narrows attention, causing irrelevant cues to be dismissed or ignored (Baron, 1986). Cohen's (1978) attentional overload theory is most applicable to the examination of functions of attentional resources during skill acquisition. This theory states that interruptions demand immediate allocation of attention, causing a shift of focus from the main task to the interruption task and reducing the cognitive capacity available for completion of the main task (Cohen, 1978). Interruptions cause information overload by confronting cognitive and attentional capacities with more cues than they can process at once. This often results in the brain allocating available attention capacity to more important aspects of a task, resulting in omission of other cues (Cohen, 1986).

Interruption characteristics, such as frequency, duration, content, complexity, timing, and the type of main task interrupted determine the effect of interruptions on performance. Shiffman and Greist-Bousquet (1992) conducted a study where participants estimated completion times of interrupted and uninterrupted tasks. They found that the interruption of a task had a "lengthening effect on perceived time duration" (Shiffman \& Greist-Bousquet, 1992, p. 9), suggesting that attention overload results in perceptions of increased time on task performance. Gillie and Broadbent (1989) also examined the effects of various types of interruptions and found that the length of an interruption did not deteriorate performance, while the content did. They also discovered that a secondary/interruption task with content similar to the main task as well as a complex dissimilar task both deteriorated performance. Iselin (1998) contributed to this when he found that interruptions of content diverse from the main task increased decision time more than interruptions of similar content as the main task. The deterioration of performance caused by interruptions illustrates their demanding effects, which require concurrent processing of overloading amounts of cues.

One of the most interesting effects of interruptions on performance is their ability to deteriorate performance on complex tasks, while facilitating performance on simple tasks (Speier et al., 1999). R. Wood's (1986) classification system for complex and simple tasks explains that complex tasks require more information processing than simple tasks and are characterised by interrelated outcomes, where processing one part of the task influences the processing of a subsequent part. Several studies have supported the finding of interruptions deteriorating performance on complex tasks and resulting in faster completion times on simple tasks (e.g., Baron, 1986; Fisher, 1998; Gillie \& Broadbent, 1989; Speier et al., 1999). Speier et al. (1999) studied the influence of interruptions on simple and complex task performance by interrupting participants and imposing a clear screen over their main computer task, asking them to complete a secondary/interruption task. They found that interruptions of complex tasks increased decision time and decreased decision accuracy, while interruptions of simple tasks decreased decision time with no effect on accuracy. Zijlstra et al. (1999) also concluded that interruptions are capable of facilitating performance, when they found participants changing their work strategy and completing the main, simple and repetitive, text-editing task faster in response to an interruption.

The facilitating effect of interruptions while performing a relatively simple task was also observed by Fisher (1998). Fisher focused more on the emotional rather than cognitive interference effect of interruptions, examining the attentional difficulties associated with interruptions and their effect on boredom. She found a positive relationship between interruptions of simple tasks and boredom reduction. The simple tasks consisted of repetitive manual assembly of objects and were perceived as less boring when accompanied by an interruption-generated stimulation. Fisher (1998) explained this finding by stating that the monotonous nature of the simple task gained "renewed energy and strengthened effort" in response to an interruption (p. 520). The reported research suggests that the type of main task interrupted and the type of interruption both determine the effect of interruptions on performance. This holds implications for various stages of skill acquisition, suggesting that interruptions are likely to have a negative effect on the initial, complex phase of skill acquisition, while facilitating performance on a well-learned routine.

Cohen's (1978) attentional overload theory offers explanation for the influence of interruptions and attention overload on simple and complex task performance. While performing a complex task, it is necessary to process a wide range of stimuli to reach successful results. During such deep and focused processing, an interruption proves harmful as it causes restrictions to attentional focus, leaving out crucial stimuli and impairing performance (Baron, 1986). While performing simple tasks, only a few cues are required for adequate performance, and an interruption helps to restrict focus back to the main task by "screening out non-essential (distracting) stimuli that would only take time away from the main task" (Baron, 1986, p. 28). Well-learned or asymptote performance does not suffer from interruption interference as it requires minimal attentional and cognitive processing. Demands on attentional resources during automatic performance may focus attention back to the main task and result in faster performance.

Figure 2 illustrates the possible effect of interruptions on progress through stages of skill acquisition. It can be seen that when the task is complex and requires high usage of attentional resources, an interruption will break focus and deteriorate performance. During Phase 3 , the task becomes automatic and simple, requiring minimal attention and an interruption will focus attention back to the task and result in facilitated performance. The model was adapted from Ackerman's (1988) and Cohen's (1978) Attentional Overload theory. However this representation, although a useful graphic illustration of some parallel processes at work during skill acquisition, is still tied to the idea of stages and the ability-performance relationship.

Figure 2 shows (after Ackerman, 1988), the common characteristics of complex tasks during the three stages of skill acquisition and the effects of interruptions during complex performance. The first stage of skill acquisition draws heavily on general cognitive abilities in three broad domains. The second stage draws heavily on perceptualspeed abilities, and the third phase draws on psychomotor abilities. Attentional resources and focus are high in demand during Phase 1 of skill acquisition, and gradually cease as the skill becomes better acquired and becomes more "simple" or straightforward, that is, once learning has occurred. An aspect of the attentional overload theory predicts that "tasks that demand considerable attention on the part of the subject would be sensitive to fluctuations in available processing capacity" (Cohen, 1978, p. 897). It follows from this preposition and from past research on the effect of interruptions on complex task performance (e.g., Baron, 1986; Speier et al., 1999) that interruptions of the slow and effortful declarative knowledge phase of skill acquisition would deteriorate speed and accuracy of performance by overloading the processes in attentional capacity. 
Kanfer and Ackerman (1989) concluded that tasks that are initially resource-dependent become progressively resource-insensitive with practice during skill acquisition. The attentional overload theory explains that interruptions may not have an overloading effect on simple, "well practiced" tasks that "require little effort" (Cohen, 1978, p. 97). Fisher (1998), Speier et al. (1999) and Zijlstra et al. (1999) observed this facilitating effect of interruptions when presented during performance on low-attention, monotonous tasks. Based on these findings and the similarity of lowattention simple tasks and Phase 3 asymptote performance of Ackerman's (1988) model, it is likely that interruptions would facilitate speed of performance during Phase 3 of skill acquisition by stimulating the performer and focusing their attention back to the main task. This is a fruitful area for future research.

In sum, this model can be constructive in providing hypotheses for experimental research that examines the effect of a range of interruptions on skill acquisition of moderately complex tasks such as word processing, and other heavily psychomotor tasks found in manufacturing (e.g., assembly line work), and retail (e.g., cashier). It is timely that, with over 40 years of research into skill acquisition, the effect of process (as described in the current work), is finally taken seriously.

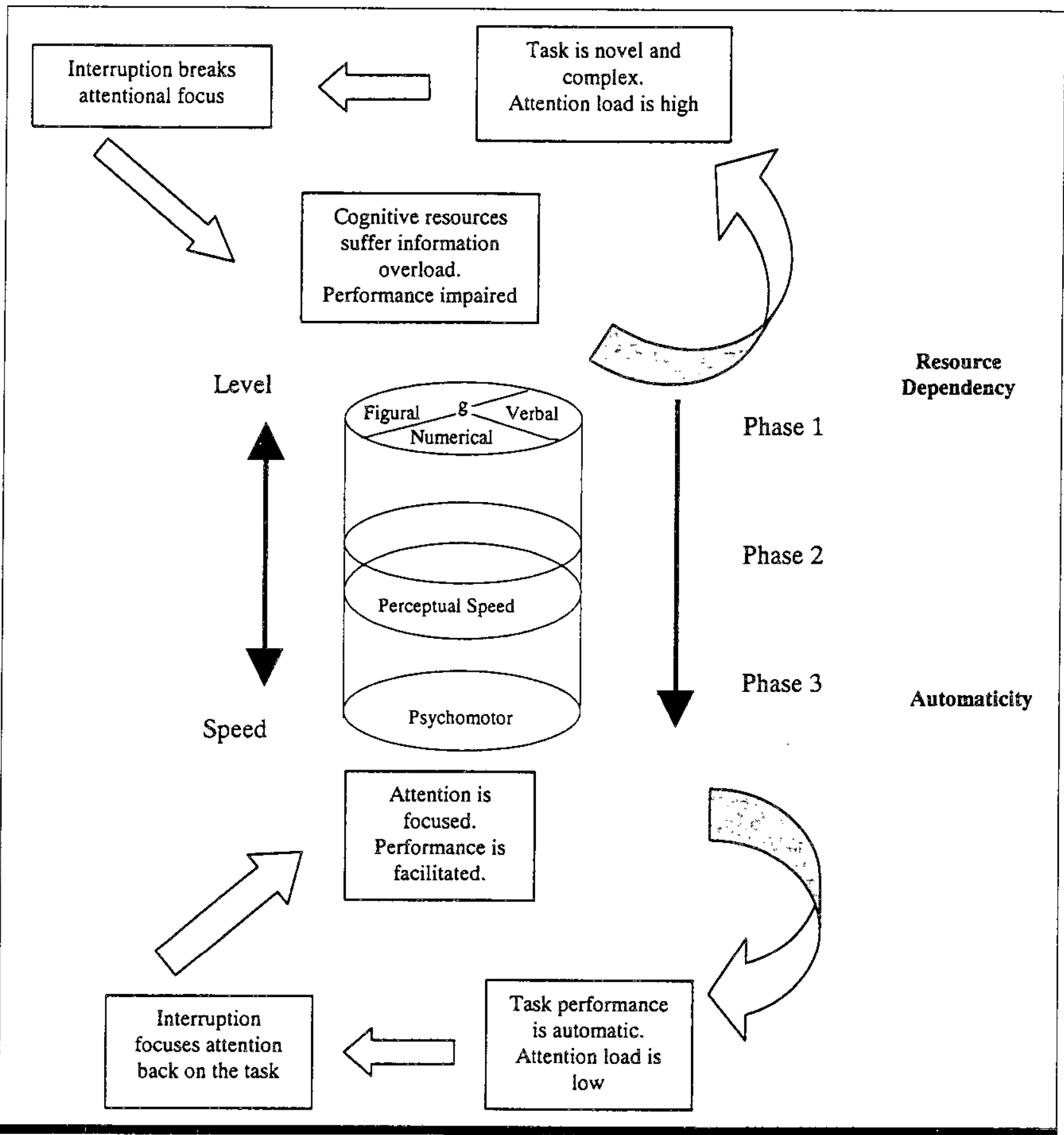

FIGURE 2

The predicted effect of interruptions on attentional resources during Phase 1 and Phase 3 of skill-acquisition.

Note: Adapted with permission from Ackerman, P.L. (1988). The cylincer section only of the model was created by Ackerman.

Determinants of individual differences during skill acquisition: Cognitive abilitiles and information processing. Joumal of Experimental Psychology: General, 117, 288-318. Copyright $\$ 988$ by the American Psychological Association. 


\section{References}

Ackerman, P.L. (1986). Individual differences in information processing: An investigation of intellectual abilities and task performance during practice. Intelligence, 10, 101-139.

Ackerman, P.L. (1987). Individual differences in skill learning: An integration of psychometric and information processing perspectives. Psychological Bulletin, 102, 3-27.

Ackerman, P.L. (1988). Determinants of individual differences during skill acquisition: Cognitive abilities and information processing. Journal of Experimental Psychology: General, 117, 288-318.

Ackerman, P.L. (1990). A correlational analysis of skill specificity: Learning, abilities, and individual differences. Journal of Experimental Psychology: Learning, Memory, and Cognition, 16, 883-901.

Adams, J.A. (1987). Historical review and appraisal of research on the learning, retention and transfer of human motor skills. Psychological Bulletin, 101, 41-74.

Anderson, J.R. (1982). Acquisition of cognitive skill. Psychological Review, 89, 369-406.

Anderson, J.R. (1995). Cognitive psychology and its implications. New York: W.H. Freeman.

Anderson, J.R., \& Matessa, M. (1997). A production system theory of serial memory. Psychological Review, 104, 728-748.

Anderson, J.R., Matessa, M., \& Legiere, C. (1997). ACT-R: A theory of higher level cognition and its relation to visual attention. Human Computer Interaction, 12, 439-462.

Anderson, J.R., \& Pirolli, P.L. (1984). Spread of activation. Journal of Experimental Psychology: Learning, Memory, and Cognition, 10. 791-798.

Antoni, C.H., \& Beckmann, J. (1990). An action control conceptualisation of goal-setting and feedback effects. In U. Kleinbeck, H. Quast, H. Thierry, \& H. Hacker (Eds.), Work motivation (pp. 62-79). New Jersey: Erlbaum.

Austin, J.T., \& Vancouver, J.B. (1996). Goal constructs in psychology: Structure, process, and content. Psychological Bulletin, $120,338-375$.

Baddeley, A. (1990). Human memory: Theory and practice. Massachusetts: Allyn \& Bacon.

Baron, R.S. (1986). Distraction-conflict theory: Progress and problems. Advances in Experimental Social Psychology, $19,1-39$

Beebe, S.A., \& Ivy, D.K. (1994, November 19-22). Explaining student learning: An emotion model. Paper presented at the 80th Annual Meeting of the Speech Communication Association, New Orleans, LA.

Bilodeau, E.A. (Ed.). (1969). Principles of skill acquisition. London: Academic Press.

Bors, D.A., \& Macleod, C.M. (1996). Individual differences in memory. In E.L. Bjork \& R.A. Bjork (Eds.), Memory: Handbook of perception and cognition (2nd ed., pp. 411-441). San Diego, CA: Academic Press.

Broadbent, D.E. (1958). Perception and communication. Elmsford, NY: Pergamon.

Bryan, W.L., \& Harter, N. (1899). Studies on the telegraphic language: The acquisition of a hierarchy of habits. Psychological Review, 6, 345-375.

Carlson. D. (1997). Experienced cognition. Mahwah, NJ: Lawrence Erlbaum.

Carlson, R.A., \& Yaure, R.G. (1990). Practice schedules and the use of component skills in problem solving. Journal of Experimenral Psychology: Learning, Memory, and Cognition, 16, 484-496.

Carroll, J.B. (1993). Human cognitive abilities: A survey of factoranalytic studies. New York: Cambridge University Press.

Cellier, J., \& Eyrolle, H. (1992). Interference between switched tasks. Ergonomics, 35, 25-36.
Cohen, S. (1978). Environmental load and the allocation of attention. In A. Baum, J. Singer, \& S. Vatins (Eds.), Advances in environmental psychology (Vol. 1, pp. 110-121). Hillsdale, NJ: Erlbaum.

Cohen, S., Evans, G.W.. Stokols, D., \&. Krantz, D.S. (1986), Behaviour, health and environmental stress. New York: Plenum.

Corragio, L. (1990). Deleterious effects of intermittent interrup. tions on the task performance of knowledge workers: A laboratory investigation. Unpubilished doctoral dissertation, University of Arizona.

Craik, K.J.W. (1948). Theory of the human operator in control systems: II. Man as an element in a control system. Brisish Joumal of Psychology, 38, 142-148.

Czaja, S.J., \& Sharit, J. (1998). Ability-performance relationship as a function of age and task experience for a data entry task. Joumal of Experimental Psychology, 4, 332-351.

Devolder, P.A., \& Pressley, M. (1992). Causal attributions and strategy use in relation to memory performance differences in younger and older adults. Applied Cognitive Psychology, 6. 132-145.

Ebbinghaus, H. (1913). H.A. Ruger \& C.E. Bussenius (Trans.), Memory: A contribution to experimental psychology. New York: Columbia University, Teachers College. (Original work published 1885)

Echt, K.V., Morrell, R.W., \& Park, D.C. (1998). Effects of age and training formats on basic computer skill acquisition in older adults. Educational Gerontology, 24, 3-25.

Ellis, H.C., \& Ashbrook, P.W. (1988). Resource allocation model of the effects of depressed mood states on memory. In $\mathrm{K}$. Fiedler \& J. Forgas (Eds.), Affect, cognition and social behaviour: New evidence and integrative attempts (pp. 25-43). Toronto: Hogrefe.

Ericsson, K.A. (1985). Memory skill. Canadian Journal of Psychology, 39, 188-231.

Ericsson, K.A., \& Charness, N. (1994). Expert performance: Its structure and acquisition. American Psychologist, 49, 725-747.

Ericsson, K.A., \& Chase, W.G. (1982). Exceptional memory American Scientist, 70, 607-615.

Ericsson, K.A., Krampe, T., \& Tesch-Romer, C. (1993). The role of deliberate practice in the acquisition of expert performance. Psychological Review, 100, 363-406.

Far, J.L., Hofmann, D.A., \& Ringenbach, K.L. (1993). Goal orientation and action control theory: Implications for industrial and organisational psychology. Intemational Review of Industrial and Organisational Psychology, 8, 192-232.

Ferro, T.R. (1993). The influence of affective processing in education and training. New Directions for Adult and Continuing Education, 59, 25-33.

Fisher, C.D. (1998). Effects of extemal and internal interruptions on boredom at work: Two studies. Joumal of Organisational Behaviour, 19, 503-522.

Fitts, P.M. (1964). Perceptual-motor skill learning. In A.W. Melton (Ed.), Categories of human learning (pp. 243-285). New York: Academic Press.

Fitts, P.M., \& Posner, M.I. (1967). Human performance. Belmont: Brooks/Cole.

Fleishman, E.A. (1972). On the relation between abilities, learning, and human performance. American Psychologist, 27, $1017-1032$.

Fleishman, E.A., \& Ellison, G.D. (1960). Prediction of transfer and other learning phenomena from ability and personality measures. Joumal of Educational Psychology, 60, 300-314.

Fleishman, E.A., \& Mumford, M.D. (1989). Individual attributes and training performance. In I.L. Goldstein (Ed.), Training and development in organisations (pp. 183-255). San Francisco: Jossey-Bass. 
Forrest-Pressley, D.L., MacKinnon, G.E., \& Waller, T.G. (1985). Metacognition, cognition and human performance. New York: Academic Press.

Geen, R.G. (1995). Human motivation: A social psychological approach. Pacific Grove. CA: Brooks/Cole.

Gillie, T., \& Broadbent, D. (1989). What makes interruptions disruptive? A study of length. similarity, and complexity. Psychological Research, 50, 243-250.

Golden, C. J., White, L., Combs, T., Morgan, M., \& McLane, D. (1999). WMS-R and MAS correlations in a neuropsychological population. Archives of Clinical Neuropsychology, $14,265-271$.

Greene. J.O., Rucker, M.P., Zauss, E.S., \& Harris, A.A. (1998). Communication anxiety and the acquisition of message production skill. Communication Education, 47, 337-347.

Gregory, A. (1998). Finding time to understand. Works Management, 51, 56-57.

Healy, A.F., \& Bourne, L.E., Jr. (1995). Learning and memory of knowledge and skills: Durability and specificity. London: Sage.

Healy, A.F., \& Sinclair, G.P. (1996). The Iong term retention of training and instruction. In E.L. Bjork \& R.A. Bjork (Eds.), Memory: Handbook of perception and cognition (2nd ed., pp. 525-564). San Diego, CA: Academic Press.

Henshaw, E.M., \& Holman, P. (1933) Manual dexterity - effects of training: II. Distribution of practice in manual dexterity. (Industrial Health Res. Bd. Rep. No. 67). London: HMSO.

Hertzog, C., Cooper, B.P., \& Fisk, A.D. (1996). Aging and individual differences in the development of skilled memory search performance. Psychology and Aging, 11, 497-520.

Hilsabeck, R.C., Schrager, D.A., \& Gouvier, W.D. (1999). Crossvalidation of the two- and three-subtest short forms of the Wechsler Memory Scale - Revised. Applied Neuropsychology, 6, 247-251.

Hogan. D.. Kwiatkowski, R. (1998). Emotional aspects of large group teaching. Human Relations, 51, 1403-1417.

Humphreys, M.S., \& Revelle, W. (1984). Personality, motivation, and performance: $A$ theory of the relationship between individ. ual differences and information processing. Psychological Review, 91, 153-182.

Ingleton, C. (1995). Gender and learning: Does emotion make a difference? Higher Education, 30, 323-35.

Iselin, E.R., (1998). The effects of intormation load and infornation diversity on decision quality in a structured decision task. Accounting, Organizations and Society, 13, 147-164.

Joesch, J.M. (1997). Paid leave and timing of women's employ. ment before and after birth. Journal of Marriage and the Family, 59, 1008-1021.

Kahneman, D. (1973) Attention and effort. Englewood Cliffs, NJ: Prentice-Hall.

Kanfer, R. (1990). Motivation theory and industrial and organisational psychology. In M.D. Dunnette \& L.M. Hough (Eds.), Handbook of industrial and organisational psychology (pp. 89-101). Palo Alto, CA: Consulting Psychologists Press.

Kanfer, R.. \& Ackerman, P.L. (1989). Motivation and cognitive abilities: An integrative/aptitude-treatment interaction approach to skill acquisition [monograph]. Journal of Applied Psychology, 74, 657-690.

Kaye, S. (1999). How to handle interruptions that steal your time. The Canadian Manager, 24, 25-26.

Kernan, M.G., \& Lord, R.G. (1989). Effects of explicit goals and specific feedback on escalation processes. Journal of Applied Social Psychology, 19, 1125-1143.

Kirmeyer, S.L. (1988). Coping with competing demands: Interruption and the type A pattern. Journal of Applied Psychology. 73, 621-629.

Kuhl, J. (1985). Volitional mediators of cognition-behaviour consistency: Self-regulatory processes and action versus state orientation. In J. Kuhl \& J. Beckmann (Eds.), Action control: From cognition to behaviour (pp. 101-128). New York: Springer-Verlag.

Kuh1, J. (1992). A theory of self-regulation: Action versus state orientation, self-discrimination, and some applications. Applied Psychology: An International Review, 41, 97-129.

Kuhl, J. (1994a). Action versus state orientation: Psychometric properties of the Action Control Scale (ACS-90). In J. Kuhl \& J. Beckmann (Eds.), Volition and personality: Action versus state orientation (pp. 9-45). Bem: Hogrefe \& Huber.

Kuhl, J. (1994b). A theory of action and state orientation. In J. Kuhl \& J. Beckmann (Eds.), Volition and personality: Action versus state orientation (pp. 9-45). Bern: Hogrefe \& Huber.

Kyllonen, P.C. (1996). Is working memory capacity Spearman's. In I. Dennis \& P. Tapsfield (Eds.), Human abilities: Their nature and measurement (pp. 49-75). New Jersey: Erlbaum.

Kyllonen, P.C., \& Tirre, W.C. (1988). Individual differences in associative learning and forgetting. Intelligence, 14 , 389-433.

Kyllonen, P.C., Tirre, W.C., \& Christal, R.E. (1991). Knowledge and processing speed as determinants of associative learning. Journal of Experimental Psychology: General, 120, 57-79.

Langan-Fox, J. (2001). Communication in organisations: Speed, diversity, networks and influence on organisational effectiveness, human health and relationships. In N. Anderson, D. Ones, H. Sinargil, \& C. Viswesraram (Eds.), Intermational handbook of work and organisational psychology (Vol. 2). London: Sage.

Langan-Fox, J., Waycott, J., \& Galna, C. (1997) Ability performance relations during skill acquisition. Australian Psychologist, $32,153-158$.

Langan-Fox, J. (in press) Skill acquisition and the development of a team mental model: An integrative approach to analysing organisational team, tasks, and content. In M. West, D. Tjosvold \& K.G. Smith (Eds), International handbook of organizational teamwork and co-operative working. London: Wiley.

Lewis, C.H. (1978). Production system models of practice effects (Doctoral dissertation, University of Michigan, 1978). Dissertation Abstracts International, 39, 5105B. (University Microfilms No. 79-07, 120)

Locke, E.A., \& Latham, G.P. (1991). Seif-regulation through goal settting. Organisational Behaviour and Human Decision Processes, 50, 212-247.

Logan, G.D. (1988). Toward an instance theory of automisation. Psychological Review, 95, 492-527.

Mandler, G. (1975). Mind and emotion. New York: Wiley.

Masson, M.E.J. (1990). Cognitive theories of skill acquisition. Human Movement Science 9, 221-239.

Masson, M.E.J. (1990). Cognitive theories of skill acquisition. Human Movement Science, 9, 221-239.

Mazur, J.E., \& Hastie, R. (1978). Learning as an accumulation: A reexamination of the leaming curve. Psychological Bulletin, $85,1256-1274$.

McGeoch, J.A. (1952). The psychology of human learning. New York: Longmans, Green, \& Co.

Mumford, M.D., Costanza, D.P., Baughman, W.A., Threlfall, K.V., \& Fleishman, E.A. (1994). Influence of abilities on performance during practice effects of massed and distributed practice. Journal of Educational Psychology, 86, 134-144.

Neves, C.M., \& Anderson, J.R. (1981). Knowledge compilation: Mechanisms for the automatization of cognitive skills. In J.R. Anderson (Ed.), Cognitive skills and their acquisition (pp. 57-84). Hillsdale, NJ: Erlbaum.

Oatley, K. (1987). Cognitive science and the understanding of emotions [Editorial]. Cognition and Emotion, 1, 209-216.

Ortony, A.. Clore, G.L., \& Collins, A. (1988). The cognitive structure of emotions. New York: Cambridge University Press. 
Palmer, J., MacLeod, C.M., Hunt, E., \& Davidson, J.E. (1985) Information processing correlates of reading. Journal of Memory and Language, 24, 59-88.

Pekrun, R. (1992). The impact of emotions on learning and achievement: Towards a theory of cognitive/motivational mediators. Applied psychology: An International Review. 41, 359-376.

Plutchik, R., \& Kellerman, H., (1980). Emotion: theory, research, and experience. New York: Acadernic Press.

Proctor, R.W., \& Dutta, A. (1995). Skill acquisition and human performance. Beverly Hills, CA: Sage.

Proctor, R.W., \& Van Zandt, T. (1994). Human factors in simple and complex systems. Boston: Allyn \& Bacon.

Rasmussen, J. (1983). Skills, rules and knowledge: Signals, signs and symbols, and their distinctions in human performance models. IEEE Transactions on Systems, Man, and Cybemetics, SMC-13, 257-266.

Riding, R.J., \& Powell, S.D. (1993). Thinking and education. Educational Psychology, 13, 217-227.

Rogers, W.A., Hertzog, C., \& Fisk, A.D. (2000). An individual differences analysis of ability and strategy influences: Age-related differences in associative learning. Journal of Experimental Psychology: Learning, Memory and Cognition, 26, 359-394.

Rosetta, Z. (2000). A metacognitive intervention in mathematics at university. Intermational Journal of Mathematical Education in Science and Technology, 31, 143-150.

Russell, A.L. (1995). Stages in learning new technology: Naive adult email users. Computers and Education, 25, 173-78.

Schmidt, K.H., Kleinbeck, U., \& Brockman, W. (1984). Motivational control of motor performance by goal setting in a dual-task situation. Psychological Research, 46, 129-141.

Schneider, W. (1985). Toward a model of attention and the development of automaticity. In M.I. Posner \& O.S. Martin (Eds), Attention and performance (Vol. 11, pp. 475-492). Hillsdale, NJ: Errbaum.

Schneider, W., \& Shiffrin, R.M. (1977). Controlled and automatic human information processing: I. Detection, search, and attention. Psychological Review, 84, 127-190.

Schumann, J.H. (1994). Where is cognition? Emotion and cognition in second language acquisition. Studies in Second Language Acquisition, 16, 231-42.

Seibert, P.S. \& Ellis, H.C. (1991). Irrelevant thoughts, emotional mood states, and cognitive task performance, Memory and Cognition, 19, 507-513.

Shiffman, N., \& Greist-Bousquet, S. (1992). The effect of task interruption and closure on perceived duration. Bulletin of the Psychonomic Society, 30, 9-11.

Shiffrin, R.M., \& Schneider, W. (1977). Controlled and automatic human information processing: II. Perceptual learning, automatic attending and a general theory. Psychological Review, 84, 127-190.
Smith, C.A., \& Ellsworth, P.C. (1985). Patterns of cognitive appraisal in emotion. Journal of Personality and Social Psychology, 48, 813-838.

Smith, C.A., \& Ellsworth, P.C. (1987). Patterns of appraisal and emotion related to taking an exam. Journal of Personality and Social Psychology, 52, 475-488.

Speier, C., Valacich, J.S., \& Vessey, I. (1999). The influence of task interruption on individual decision making: An information overload perspective. Decision Sciences, 30, 337-360.

Sylwester, R. (1994). How emotions affect leaming? Educational Leadership, 52, 60-65.

Underwood, B.J. (1961). Ten years of massed practice or distributed practice. Psychological Review, 68, 229-247.

Underwood, B.J., \& Schulz, R.W. (1959). Studies of distributed practice: XIX. The influence of intralist similarity with lists of low meaningfulness. Journal of Experimental Psychology, $58,106-110$.

Welford, A.T. (1968). Fundamentals of skill. London: Methuen.

Wellman, H.M. (1985). The origins of metacognition. In D.L. Forrest-Pressley, G.E. MacKinnon, \& T.G. Waller (Eds.), Metacognition, cognition and human performance (pp. 123-145). Orlando: Academic Press.

Wickens, C.D. (1980). The structure of attentional resources. In R.S. Nickerson (Ed.), Attention and performance VIII (pp. 239-257). Hillsdale, NJ: Erlbaum.

Wickens, C.D. (1984). Processing resources in attention. In R. Parasuraman \& R. Davies (Eds.), Varieties of attention (pp. 63-102). New York: Academic Press.

Willoughby, T., Waller, T.G., Wood, E., \& MacKinnon, G.E. (1993). The effect of prior knowledge on an immediate and delayed associative learning task following elaborative interrogation. Contemporary Educational Psychology, 18, 36-46.

Woltz, D.J. (1988). An investigation of the role of working memory in procedural skill acquisition. Journal of Experimental Psychology: General, 117, 319-331.

Wood, J.V., Saltzberg, J.A., \& Goldsamt, L.A. (1990). Does affect induce self-induced attention? Journal of Personality and Social Psychology, 6, 899-908.

Wood, R.E. (1986). Task complexity: Definition and construct. Organizational Behaviour and Human Decision Processes, 37, 60-82.

Wood, R.E., Mento, A.J., \& Locke, E.A. (1982). Task complexity as a moderator of goal effects: A meta-analysis. Journal of Applied Psychology, 72, 416-425.

Zijlstra, F.R.H., Roe, R.A., Leonara, A.B., \& Krediet, I. (1999). Temporal factors in mental work: Effects of interrupted activities. Joumal of Occupational and Organisational Psychology, $72,163-185$ 